\title{
La presencia de Eros en la poesía dramática de Sófocles
}

\author{
María InÉs Saravia de Grossi \\ Universidad Nacional de La Plata \\ Argentina
}

\section{Título. A presença de Eros na poesia dramática de Sófocles}

REsumo. Eros está presente em toda a literatura grega. A expressão característica dessa força irracional é a afirmação de que ninguém, nem homens e nem deuses, resiste à sua influência. Nestas páginas realiza-se a análise filológico-literária do III estásimo da Antígona e do I estásimo das Traquinianas, na qual se descreve o poder envolvente de Eros, que domina todo o universo, muda as coisas e vem pelo mar.

Palavras-Chave. Sófocles; drama; Eros; Antígona; Traquinianas; estásimos.

El amor en toda la literatura griega está inspirado por una divinidad: Afrodita o Cipris y encarnado en un dios: Eros. El poder de Afrodita no se confina en el poder sexual sino que es una fuerza que atañe al universo; con su presencia se avasalla toda posibilidad de contención. Junto con Eros representa, asimismo, la pasión por los alimentos, la bebida, el canto y la danza e, inclusive, las condolencias; además, se la conecta con la destrucción bélica'. En esta comunicación analizamos el estásimo III de Antígona y el estásimo I de Traquinias por la semejanza de la temática representada por Eros o Afrodita.

Email: marinesaravia@yahoo.com.ar

Centro de Estudios de Lenguas Clásicas (AFG).

${ }^{1}$ Cf. Th.C.W. Oudemans y A.P.M.H. Lardinois, Tragic Ambiguity. Anthropology, Philosophy and Sophocles' Antigone, Leiden, Brill, 1987, p. 95 . El fragmento 941 de Sófocles se ocupa del tema e influyó, a criterio de M. VAN DER VALK (Remarques sur Sophocle, Trachiniennes: 497-530, REG 80, 113-129, 1967) sobre el Hipólito de Eurípides. Cf. J. Romilly (La Tragédie Grecque au fil des ans, Paris, Les Belles Lettres, 1995, p. 129133), quien afirma que el tema ya se encuentra en Homero (Il. 14.198-99), en el Himno a Afrodita, Fr. 1.2-5 de Safo y Anacreonte Fr. 28. El tema del amor en Hipólito merece una consideración especial, pues la interiorización del sentimiento no indica un progreso en la autonomía del alma, todo lo contrario. Más bien la responsabilidad humana parece menor que en las piezas de Sófocles, pues Artemisa confirma en el final de la obra que sólo Cipris es responsable. Por tanto parecería que la responsabilidad humana en las dos piezas Hipólito (525-64; 1268-82) y Traquinias (497-530) va en disminución. Para Eurípides los mortales no son responsables de sus amores y este mal es involuntario. 


\section{Antígona: estásimo III}

En el estásimo III Antígona, Hemón está enamorado de la hija de Edipo, pero sus sentimientos no le impiden actuar con sensatez frente a su padre. Es un joven que asombra, al principio, como ejemplo de moderación y amor filial, pero, a medida que Creonte expone su pensamiento ante su heredero, principalmente aquél en los que muestra su desavenencia profunda con respecto a Antígona, por ejemplo cuando afirma que la mujer deviene un frío objeto de placer $(650)^{2}$ y la define como É $\lambda$ Kos, vó oos,

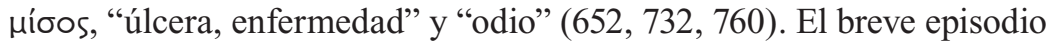
III rápidamente cambia de tono y el padre, que paradójicamente era, en la primera parte de la obra, el hombre honesto, decente, que apelaba a los impulsos racionales de su temperamento, logra que su hijo se retire con odio, con una violencia que raya en el delirio, imposible de revertir. En este marco el joven se animaliza, como relata más tarde el mensajero $(1206,1209,1214,1231)^{3}$. El Corifeo teme acertadamente por el futuro de Hemón y los ancianos cantan el Estásimo III, donde manifiestan el temor hacia los efectos del poder de Eros. Formalmente, el canto es una señal del dios, y es común que esto forme la primera parte de un himno, pero en este caso no continúa la plegaria.

La presencia de Eros expone la fragilidad del hombre y de los sufrimientos ${ }^{4}$. Contrariamente a lo que podría esperarse, el Estásimo III no guarda el tenor de un canto romántico, pues la invocación se efectúa a un poder entronizado entre las leyes más grandes, absolutamente destructivo y que casi siempre engendra locura (798-99). El canto inaugura los Coros de la segunda parte de la obra, en la que aparecen las fuerzas irracionales que ha despertado todo el accionar violento de Creonte $^{5}$. El estásimo comienza con un paralelismo y anáfora (781-84):

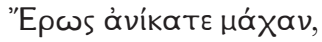

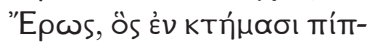

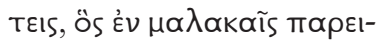

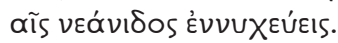

${ }^{2}$ El lenguaje empleado por Creonte tiene un tono cruelmente sexual, como en el verso 569 y otros. Su postura hace que tomemos partido por Hemón, sin saber todavía qué dirá ante su padre.

${ }^{3}$ Estamos de acuerdo con $\mathrm{CH}_{\mathrm{H}}$. Segal (Tragedy and Civilization. An Interpretation of Sophocles, Cambridge, Harvard University Press, 1981, p. 191) en que la cacería de animales se relaciona con la esfera erótica, y el lenguaje empleado por el mensajero connota esa actividad.

${ }^{4}$ R.C. JebB, Sophocles. Antigone, Cambridge, 1900 (repr. Amsterdam, Hakkert, 1971), p. 166-7.

${ }^{5}$ Cf. nuestrolibro, Sófocles, una interpretación de sus tragedias, La Plata, EdULP, 2007, p. 118. 
Eros, inconquistable en la batalla,

Eros, el que caes en las riquezas,

El que pernoctas en las

suaves mejillas de una joven.

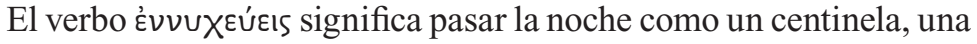
imagen militar, un oxímoron del estilo sofócleo. En los versos siguientes se menciona que Eros transita por el mar y frecuenta las cabañas campestres, los lugares más lejanos donde los hombres se instauran. El agua actúa como buena conductora de electricidad y el dominio envolvente de Eros hace que sea imposible escapar en ningún sitio. Luego se explicita que ni los inmortales ni los hombres efímeros evitan la locura con la que Eros

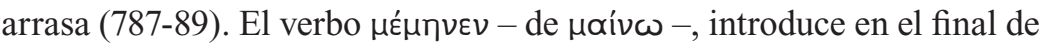
la estrofa un lenguaje siniestro que anticipa lo que vendrá, al menos en relación a la proyección dramática entre Creonte y Hemón. ${ }^{6}$

En la segunda mitad del canto se presenta el uso anafórico del pronombre oú, personificación del poder de Eros cuyos efectos están ejemplificados en particular (791-94):

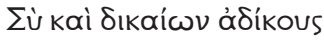

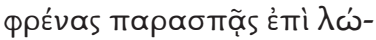

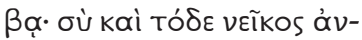

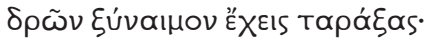

Tú arrastras los pensamientos

de justos a injustos con oprobio, y tú has excitado esta querella familiar de hombres.

La antistrofa (791-800) ejemplifica la subversión del orden cultural. El

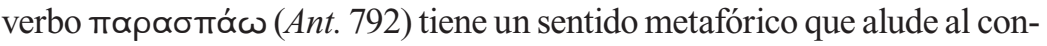
ductor de caballos que lleva el carro fuera de su curso ${ }^{7}$. En el centro las pa-

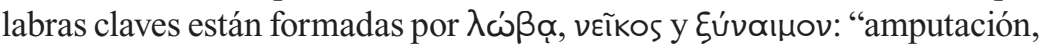
querella" y "consanguíneo". Puntualmente, en forma sintética describen el conflicto trágico de la obra. Con la palabra $\lambda \omega \beta \alpha$ se involucra un corte, amputación o desgracia, con ella se alude a las muerte de los hermanos.

En el episodio V, en el discurso de Tiresias (1064-1090) reaparece un término de la misma raíz $\lambda \omega \beta \eta \tau \tilde{p} \rho s$ (1074) como una síntesis de

\footnotetext{
${ }^{6}$ Cf. A.L. Brown, Sophocles: Antigone, Warminster, Aris and Phillips, 1987, p. 187, n. 790. ${ }^{7}$ Cf. R.C. JeBB (1900,p. 146). El mismo verbo ocurre en Electra 732, a propósito de la descripción del accidente que produce la "muerte" de Orestes y en Edipo en Colono 1185, cuando Antígona recomienda a su padre escuchar a Polinices, que la violencia no lo apartará de su sentimiento.
} 
las imágenes de oт๙aparuós que detalla el adivino cuando describe la subversión de la naturaleza que ocasionan los cadáveres insepultos en las afueras de Tebas. El resultado de la obsesión de Creonte produjo la con-

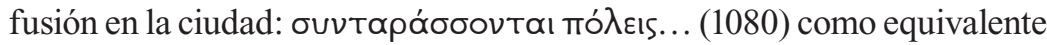
a la peste que se manifiesta en el prólogo de Edipo Rey.

Cuando Tiresias se retira iracundo, Creonte tiembla como una hoja (1095-97). Describe el pánico y la inestabilidad con el verbo tapóoбouđı (1095), como los efectos de Eros, con obnubilación en su corazón, también como Eros. En el verso 797 Eros está descrito como sentado en el trono de las leyes que existen desde los principios de la humanidad. Aquí Creonte encuentra que se ha quedado flotando en el vacío y que vertiginosamente es llevado a su ruina por sus propias iniciativas. Desde que Tiresias abandona el escenario, Creonte se comporta como un cadáver viviente, pues no tiene poder de decisión ${ }^{8}$. Creonte está incluido en la devastación de la ciudad que ha descrito Tiresias.

Nعĩ̌os como "querella" resulta paradójico cuando se habla de Eros,

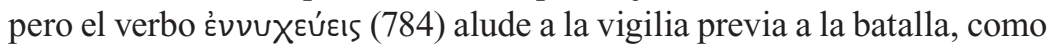
se ha dicho anteriormente 9 . Neĩ ós se menciona en la Párodos (111), a propósito del triunfo; en verdad, el canto irradia un tono hipórquemático porque los ancianos festejan el dominio de Tebas sobre el invasor y desconocen los acontecimientos que tuvieron lugar en la noche, pasando las murallas de la ciudad. La palabra veĩkos estremece al público que sabe que no sólo no han finalizado las hostilidades sino que todavía no ha comenzado, acaso, lo peor. Además el sustantivo actualiza el nombre de Polinices, el de muchas querellas, el pendenciero.

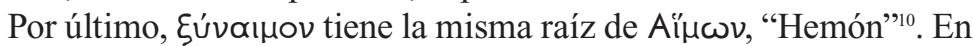
el episodio II, en el encuentro con Antígona que irrita decididamente a Creonte, menciona que por más hermana suya que sea la madre de Antígona, igual castigará a la joven por su desobediencia (486 y 488). Creonte

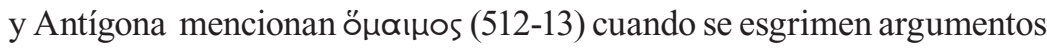
en relación al trato igualitario ante los hermanos. Por medio de la raíz aíuse alude a los hermanos muertos, abrazados en combate; a Antígona y su madre; a Creonte y su lazo familiar más cercano: el joven Hemón. Esta

${ }^{8}$ Para Aristóteles en Poética 1450b.2, el carácter se delinea en acción, el momento en que adoptan las decisiones que las circunstancias requieren. Creonte completa la parábola.

${ }^{9}$ Cf. Brown (1987, p. 187, 784), quien afirma que la metáfora bélica concuerda con todo

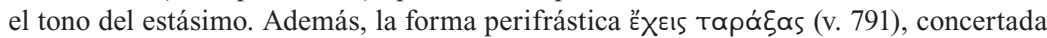
con Eros, produce desorden, problemas, distracción, agitación, disturbios, excitación.

${ }^{10}$ Oudemans y Lardinois (1987, p. 84) considera que Hemón es la imagen del esclavo de Eros. 
secuencia se vuelve paradójica en la segunda parte de la obra justamente con respecto a Creonte, porque entonces se trata de su único hijo vivo.

Por consiguiente, las palabras proyectan sus sentidos en toda la obra; el estásimo marca un punto de inflexión, pues inaugura los cantos corales donde predomina la potencia báquica, irracional, que no se ajusta precisamente al orden pretendido por Creonte.

En la segunda mitad de la antistrofa (795 y ss.), vikã ... ï $\mu \varepsilon \rho o s$, "vence el deseo...", Eros más cerca justamente de ípєpos. La influencia amorosa se da a partir de los ojos de la novia, deseada como esposa ${ }^{11}$. El poder de Eros abreva en las mejillas de una niña o en los ojos de una novia, lo cual suena paradójico, pues no hay signos en el canto de que Eros sea positivo para la humanidad.

Eros además está sentado en el trono de las leyes magnánimas del principio de todos los tiempos. Un lugar privilegiado, sentado como igual ante la majestad de la ley, el asesor de la autoridad. Es evidente la alusión directa a Hemón, el príncipe de Tebas, en cuanto de este modo Eros implica convención, y se sabe que Hemón se ajusta a las convenciones sociales cuando anhela casarse con Antígona. Y como una razón, el canto explica 'pues la diosa Afrodita juega invencible' (789-800). Aquello que trae locura y ruindad para los humanos - Afrodita y Eros, en este canto intercambiables, como casi siempre - es un juego de niños, o incluso una burla. ${ }^{12}$

No bien comienza el episodio IV, como una acotación escénica, los ancianos introducen a Antígona en la acción y expresan 'veo a Antígona en el tálamo no nupcial, sino de muerte' (801-5). Generalmente Tó $\lambda \propto \mu \circ v$

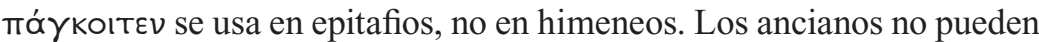
contener los arroyos de lágrimas.

El canto ha comenzado con una tercera persona singular que designa a Eros, luego lo señala incriminando su actividad con el pronombre de la segunda persona, junto a Afrodita y a $\theta \varepsilon \sigma \mu o i ́$, las leyes primordiales de

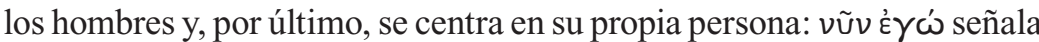
el principio del fin, pues los ancianos quieren mantenerse al margen de la vorágine que describen. Ellos no resistirán las leyes escritas por Creonte, están francamente motivados a rebelarse. Las $\theta \varepsilon \sigma \mu o i ́$ del verso 800 aluden

${ }^{11}$ L. CAmpBell (Sophocles. The plays and fragments, v. 1 y 2, Oxford, Oxford University Press, 1879 y 1881) afirma que el deseo se presenta como una emanación desde el mismo objeto deseado, como algo invasor, por tanto no surge a partir del sujeto contemplativo (v. 1, p. 523).

${ }^{12}$ Cf. M. Griffith, Sophocles. Antigone, Cambridge, Cambridge University Press, 1999, p. 260, n. $799-800$. 
a las ớypaфo vómoı, los derechos consuetudinarios que los pueblos se ocupan en resguardar, y que otorgan cohesión social a las comunidades en cuanto albergan el reservorio de la memoria colectiva. Estas difieren de las otras mencionadas a continuación (802), las leyes que impone el nuevo gobernante y que chocan con las anteriores, puesto que no admiten más alternativas que las propias.

Creonte ni se plantea que hay razones humanitarias para tener en cuenta en cada acto de gobierno; con más razón si se trata de su familia. Por lo tanto si los ancianos no comparten las nuevas, están con las leyes ancestrales, una manera de definir a quién acompañarán a continuación,

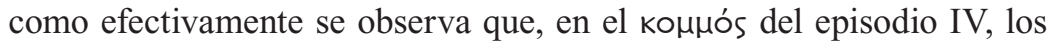
ancianos cantan en sintonía con la joven; en cambio, en el Éxodo, cuando Creonte clama vanamente por los errores irreparables, como lo había anticipado Tiresias, lo hace sin el contrapunto de los ancianos.

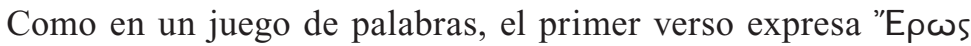

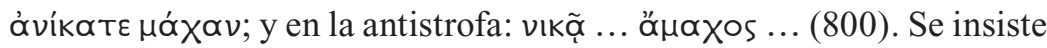
en que Eros permanece inconquistable y su triunfo llega a ser inevitable (788-90), e incluso que su poder tiene cierta legitimidad. 'E $\mu \pi \alpha i ́ \zeta \varepsilon ı$ suena irónico. Como un niño Afrodita juega con el destino de los hombres. Los espectadores lo vivencian como una burla que propone Eros - y Afrodita -. Este final anuncia el desmembramiento de la familia de Creonte, quien ha permanecido en el escenario probablemente, por lo tanto está dirigido a él más directamente, de ningún modo puede interpretarse que invoca el amor romántico de los jóvenes. ${ }^{13}$

En el estásimo III Eros aniquila todas las fronteras; por su propia naturaleza actúa úmepтóvтıos, se desplaza allende el mar, más allá de lo visible o conocido, proviene de los recintos salvajes más inciertos (785-86). Cuando el Mensajero inaugura el éxodo, el tono reposado y filosófico despierta curiosidad e intriga. El heraldo comienza su discurso con palabras que caracterizan el pensamiento de Sófocles, como Tú Xワ,

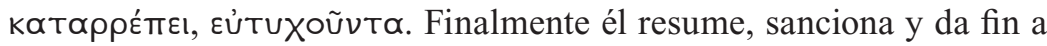
la actuación de las fuerzas irracionales que se desataron a partir del es-

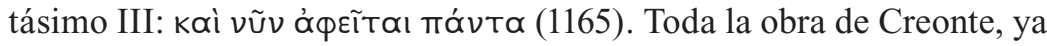
sea en la vida pública como en la vida privada, se ha esfumado pues se

${ }^{13}$ Cf. R.P. Winnington-Ingram (Sophocles. An Interpretation, Cambridge, Cambridge University Press, 1980, p. 96-7): 'thus, in the present ode, if they are thinking of Haemon, the poet invites his audience to think of the unequal battle which Creon has joined with a great cosmic force.' 
ha desguarnecido todo límite en el trayecto por donde irrumpe Eros ${ }^{14}$. Este último Mensajero lo confirma.

El tono angustiante del estásimo III adelanta el tono del hipórquema en el estásimo $\mathrm{V}$, cuando la invocación a Baco dista de ser un canto de alegría, pues en esa oportunidad el Coro trasunta angustia, desazón, y una preocupante intranquilidad.

\section{Traquinias: estásimo I}

Cuando comienza la obra en el prólogo, Deyanira repasa su existencia solitaria y recuerda a todos sus pretendientes, es decir, a Aqueloo en sus formas diversas: como toro, como dragón abigarrado y sinuoso, y también con cuerpo viril y cabeza de buey. ${ }^{15}$

En el episodio I en el discurso de Licas, Zeus es mencionado como el único dios a quien se atribuye la responsabilidad de la victoria sobre Ecalia. En cambio, el relato del Mensajero a los habitantes de Traquis menciona a Eros como la divinidad bajo la cual Heracles actuó, razón por la que Deyanira ha sido desplazada a un segundo plano.

En suma, tanto Licas como el Mensajero declaran que la toma de Ecalia y la muerte de Eurito se debieron a Yole. Desde el punto de vista compositivo, el debate entre los hombres produce un retraso en la acción de la trama. Sófocles expone el recurso de no enterarnos nosotros directamente de la verdad de los hechos relatados sino lo que otro escuchó de Licas, cuando contó acerca de los acontecimientos que ocurrieron a Heracles $^{16}$. Este vestigio de subjetividad colabora, junto con el retraso de la

${ }^{14}$ M. Benavente Barreda (Sófocles. Tragedias y Fragmentos, Madrid, Ed. Clásicas, 1999, p. 442, n. 60) afirma: 'a lo largo de este canto hay una clara contraposición entre el amor de los seres vivos, que vence pujante por doquier...y el "amor" de Hades, dios de los muertos, que en el mundo subterráneo tomará a la doncella condenada como esposa'. La afirmación contradice lo que nosotros proponemos, acerca de que no hay ningún dato cierto en el canto de los ancianos de que Eros sea un sentimiento positivo, constructivo y de unión entre los hombres. Sí aceptamos la ambivalencia o ambigüedad de la imagen del lecho común a todos como metáfora de la muerte.

${ }^{15}$ Para el tema de los monstruos, cf. E. Sorum, Monsters and the Family: the Exodos of Sophocles' Trachiniae, GRBS 19, 59-73,1978. Ciertamente en Traquinias aparecen más monstruos que en todas las tragedias juntas. Curioso que en una obra donde se expongan las pasiones que hacen a la vida humana intervengan tantos monstruos. Todas las criaturas mencionadas tienen como común denominador el cambio de forma, combinaciones de animal y humano, tres cabezas, tamaño enorme y piel invulnerable. Están todos más allá del control humano por su fuerza excepcional y su habitat. Todos representan una amenaza para el héroe y la sociedad.

${ }^{16}$ Algo así como el discurso del mensajero en Áyax (748-83), que refracta la voz de Calcas 
acción, con un margen de inseguridad que comienza a corroer a Deyanira, pues crea intriga, inquietud y sospechas. ${ }^{17}$

Propongo demostrar que en este estásimo I reposa el centro neurálgico de la obra, cuyo tema consiste en plasmar las conquistas de amor y correlativamente los sentimientos de odios desenfrenados. Visto así, el canto conecta directamente sobre el grado de pasión que se despliega en la obra ${ }^{18}$. El estásimo I evoca la lucha aparentemente final entre los dos pretendientes; el esfuerzo de Heracles para la conquista de Deyanira en el pasado remoto. Es decir, el tema cantado evoca el amor de Heracles $\mathrm{y}$ el énfasis puesto en la contienda para obtenerla como un ỡ $\theta \lambda \circ v$. Otra vez Sófocles ejemplifica en este Estásimo la voracidad frenética de Eros.

En relación con el tiempo cronológico, el estásimo canta lo más antiguo, es decir, el pasado remoto; los Mensajeros en el episodio I, lo más reciente, el pasado inmediato, es decir, la toma y conquista de Ecalia ${ }^{19}$.

en una tercera instancia, e irremediablemente la subjetividad del relato coadyuva con la confusión en la interpretación del mensaje.

${ }^{17}$ Mensajero: Yo he oído que este hombre (Licas) decía a muchos testigos allí presentes que aquél tomó a Eurito y a Ecalia, la de altas torres, por esta joven. Que Eros, solo entre los dioses, lo golpeó con un toque mágico para armarse con la espada, por estas razones, no por los servicios hacia los lidios ni por los trabajos para Onfale, ni (lo golpeó) la muerte por el precipicio, de Eurito. (Eros), al que ese ahora contraría (351-358). Un oxímoron hay

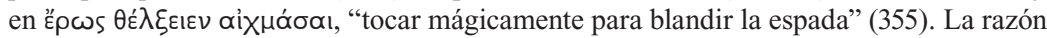
real fue Eros, dar el toque mágico para la guerra, como en el verso 784 Antígona imagen militar para la joven enamorada.

${ }^{18}$ Cf. C. Gardiner, The Sophoclean Chorus. A study of Character and Function, Iowa, University of Iowa Press, 1987, p. 125 y ss. L. CAMPBell (1881, v. 2, p. 241) lo llama “Oda de Reminiscencia" (497-530), donde Afrodita es invocada con pavor más que con placer. Los dáctilos y anapestos dan un aire heroico a la descripción de la contienda. El estásimo II es llamado "Oda de la esperanza" (633-662), anticipa la llegada de Heracles y la restauración de su amor. El canto tiene más regularidad y balance. El "himno a la alegría" (205-24) trasunta cierto carácter salvaje, perceptible aún aparte de la música frigia. Como en Edipo Rey, la párodos se compone sin anapestos y los anapestos que acompañan la entrada de Heracles pertenecen a los lamentos. Pasajes commáticos de la obra: 1), cuando se relata el suicidio de Deyanira y 2) antes de la entrada de Heracles, dos hemicoros dialogan líricamente. Pero las rhesis de Heracles, interrumpidas una y otra vez con espasmos anapésticos, toman el lugar de un más extendido commós.

${ }_{19}$ Para el estudio del estásimo cf. F.M. Pontani, Lettura del $1^{\circ}$ Stasimo delle Trachinie, Dioniso (N.S.) 12.4, 233-42, 1949. Asimismo cf. VAN DER VALK (1967, p. 115) quien comenta que, cuando el Coro describe, formula preguntas. Las interrogaciones y reiteraciones para la descripción parecen llamativas; pero, en verdad, no deberían sorprendernos en cuanto las mujeres no han estado presentes durante los acontecimientos descriptos. Van der Valk menciona el carácter ambivalente del amor, que ejemplifica en la oposición del epodo (vv. 525 y 530). A.S. Mac DevitT (Sophocles Trachiniae 526-530, Hermes 110.2, 245-47, 1982, p. 246) afirma: 'in singing of the fight with Acheloo, the Chorus at once recalls 
El relato de las dos batallas pone en evidencia el poder devastador de Cipris que extermina a Heracles y Deyanira. En los episodios los hechos se apoyan en el tiempo narrativo que cohesiona la historia ${ }^{20}$. En el Estásimo I las coreutas se mencionan como testigos (526), dado que la introducción al óyćv para conseguir a la novia supone una actuación con público ${ }^{21}$. El canto ofrece tal claridad icónica que proporciona una representación diáfana y ajustada de cómo Heracles ha vencido en su primera y última conquista. El Coro abastece ambas contiendas: la del pasado inmediato y la del pasado remoto por medio del tiempo mítico y realzando la imagen de un Heracles tradicional. En ambas situaciones las mujeres permanecen alejadas de él.

Al recordar la lucha desenfrenada, las coreutas permanecen junto a la heroína y levantan la moral a Deyanira después de conocer a la joven Yole. Influye como un hipórquema invertido, en el sentido en que la aceptación de Deyanira ante las mujeres cautivas parece de buen agüero pero, a continuación, las mujeres de Traquis adelantan el horror. En su descripción trazan el cariz de los temperamentos y de las acciones venideras $^{22}$. Acto seguido detallamos el análisis:

A: a modo de un priamel negado se menciona la capacidad de Ci-

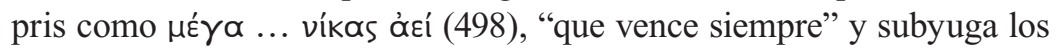
tres ámbitos del universo: Zeus, Hades y Poseidón ${ }^{23}$. Con cierto tono de

the past and suggests the present, so that we are made aware that the same powers are still operative. Aphrodite works her will upon men now, even as she did then'. El Coro le habla como una madre (526), lo cual significa para el crítico: 'I speak with a mother's care and concern', palabras que señalan aún más la soledad de Deyanira en aquel momento y en el presente.

${ }^{20}$ Cf. G.H. Gellie, Sophocles. A Reading, Melbourne, Melbourne University Press, 1972, p. 54-5. El autor es claro cuando establece que el plano narrativo enfoca la vida rutinaria de Deyanira; mientras el plano mítico realza la figura del multifacético río Aqueloo.

${ }^{21}$ P.E. Easterling (Sophocles. Trachiniae, Cambridge, Cambridge University Press, 1982,

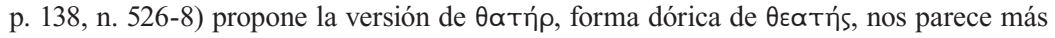
aceptable, dado que ellas relatan como un espectáculo al que han contemplado como espectadoras. Las lecciones que prefieren $\mu$ ó тᄁ $\rho$ hacen referencia al relato de la lucha que hacían las madres, pues en este caso, ellas no lo vieron. Para estas posibilidades cf. BEnAVENTE BARREDA, 1999, p. 491-92, n. 28.

${ }^{22}$ Cf. Gardiner (1987, p. 138) para quien la acción del drama procura imperativamente la sujeción a Dike, el orden del universo. Es evidente la estrecha correspondencia entre métrica y semántica. A- $\alpha$ ' y epodo. Varían ritmos logaédicos con anapestos y yambos. Los anapestos indican la llegada de los combatientes (vv. 506, 510, 513, etc.). Los ritmos interrumpidos del epodo ayudan a expresar la lucha entre ellos. Los hechos felices se marcan con troqueos y glicónicos. Cf. CAMPBell (1881, v. 2, p. 289-90, n. 498-530).

${ }^{23}$ Cf. Easterling, 1982, p. 134, n. 498-500. La tripartición del universo, es decir, el cielo, el mar y el mundo subterráneo. Además, Zeus es reconocido como un amante notorio, lo mismo ocurre con Poseidón, aunque no en tan gran escala, mencionado como pais Diós. 
asombro, el Coro señala el carácter engañoso ớ Tó тđбєv (499) de Cipris. Comienza la lucha por amor y el Coro se pregunta anafóricamente quiénes eran los contrincantes: tíves (503 y 504). Es el momento en que comienza la narración heroica. En $\alpha$ ' se responden las preguntas anteriores, a modo

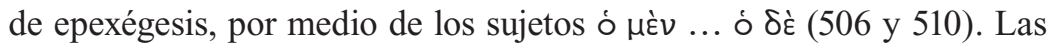
respuestas a los interrogantes están en los nombres de los contrincantes. Aqueloo es descrito como фóoua taúpou, sugiere una aparición que produce impresión por la vista ${ }^{24}$. Efectivamente Aqueloo tiene un aspecto bestial que coincide con la descripción que efectúa Deyanira en el Prólogo (9-15). Estilísticamente, la identificación de los contrincantes se establece por medio de un quiasmo, dado por el lugar de origen de los pretendientes

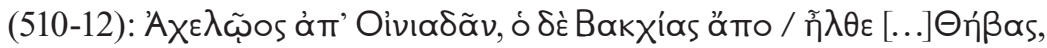
"(uno era) el Aqueloo de Eníada, el otro vino de la báquica Tebas."

Aqueloo proviene de Eneo, raíz de oĩvov, y Heracles de Tebas por adopción, cuyo epíteto es Bakxías, en alusión a la irracionalidad de Dionisos $^{25}$. El paralelismo de la construcción equipara a los contrincantes ${ }^{26}$. Aqueloo toma la forma de toro como la más admirable ${ }^{27}$. Por otra parte, las armas de Heracles constan de arco, lanza y clava. ${ }^{28}$

A Hades se le conoce el rapto por amor de Perséfone, la única.

${ }^{24}$ Cf. CAmpBell, 1881, v. 2, p. 291, n. 507-8.

${ }^{25}$ Cf. D. CARlisky Pozzi, Crisis y remedio en el mito y el teatro: Las Traquinias, La Plata, EdULP, 1999, p. 91.

${ }^{26}$ Cf. B. Heiden (Tragic Rhetoric. An Interpretation of Sophocles' Trachiniae, New York, Peter Lang, 1989, p. 27), quien advierte que tanto Dionisos como Aqueloo representan vida y muerte; paz y violencia, forma y deformidad. El dios Aqueloo representa una fuerza especial de poder vital, pero nadie reconoce su carácter inevitable. A pesar del triunfo de Heracles, se espera una venganza.

${ }^{27}$ Easterling, 1982, p. 136, n. 509. Asimismo Heiden (1989, p. 25) afirma lo siguiente: 'all three of the river's shapes "represent male sexuality in fabulous form, as fantasized by a frightened young girl". The bull of course seems acceptable as a figure of masculinity, its horns suggesting the wooer's power of penetration and his abundance of vital fluid. A coily snake, however, is not much like an erect phallus; the coils may indicate rather a power to enfold more suggestive of female than male anatomy. The third form is actually a combination of two forms, bull and man, from whose dark beard streams of fountainwater are sprinkled. According to Wender "the water pouring out of a bush of hair seems like another fairly transparent image," by which she means that it represents the male' semen does not spurt from a bush of hair. [...] the three forms of Achelous represent first masculine sexuality, then feminine sexuality, and finally a combination of masculine and feminine.' La polaridad Aqueloo - Heracles (por ejemplo lo estable y lo inestable; entre lo sólido (Heracles) y el río (Aqueloo) desaparece cuando se advierte que ambos son víctimas de Afrodita. Incluso Afrodita misma ha nacido del agua, y su efecto sobre los enamorados es derretirlos, licuarlos.

${ }^{28}$ Heracles representa la figura heroica ideal. Paradójicamente su nombre supondría que Hera 
Las jóvenes de Traquis insisten en que Cipris presenciaba la lucha

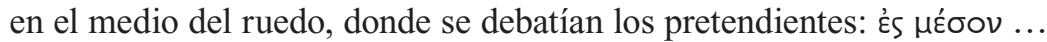

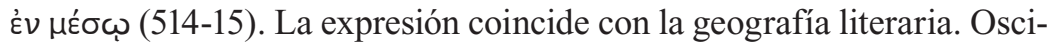
lación y ambigüedad permanente entre el aspecto amable del amor frente

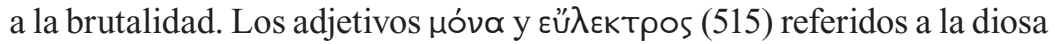
se contraponen a ơo $\lambda \lambda \varepsilon \tilde{s}$, "todos juntos" (513), el predicativo de los dos rivales. Afrodita está sola, y ciñe la vara de la justicia en medio del ruedo

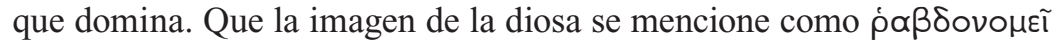
$(516)=$ : que ciñe la vara de la justicia, forma todo un oxímoron, pues lo

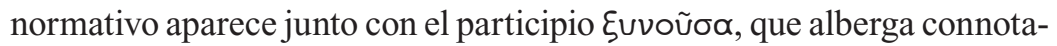
ciones eróticas - a propósito de la छuvovoía propia del matrimonio. Afrodita contempla cómo Deyanira permanece en soledad, una víctima que se convierte más tarde en victimario, si bien nunca deja de ser sacrificada.

El epodo comienza con abundantes imágenes auditivas ơvó́ $\mu ı \gamma \delta$, тátayos, бтóvos, que describen el estruendo de la batalla: el silbido de las flechas el chocar de los cuernos de toro y los saltos cuerpo a cuerpo (517-23). El rugido de ambos no es de dolor sino de esfuerzo. Dichos versos presentan el 'esquema pindárico', señalado por los escoliastas como la única vez en Sófocles que el verbo precede el nombre ${ }^{29}$. En el punto culminante de la batalla el canto alberga reminiscencias de epinicio. Las imágenes visuales en $\alpha$ y epodo junto con las auditivas en $\alpha$ ' connotan el compromiso integral en la lucha.

Entre el fragor de la batalla, descrito en la primera parte del epodo y el silencio solitario de la novia, en los últimos versos, hay un abismo en el cual se desprende que Heracles ha triunfado. No obstante, a pesar de que el héroe ha salido victorioso, el vocabulario empleado a continuación

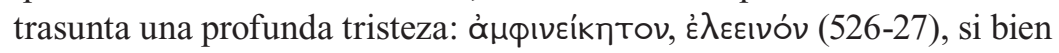
llega a ser algo inesperado en esa situación puntual, no sorprende. Luego

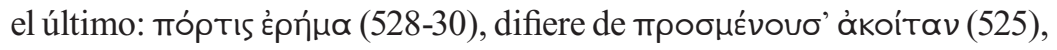
cuando Deyanira anhelaba que Heracles fuera su esposo. Se esperaría un final feliz en el Coro, en cambio las expresiones entrañan desolación ${ }^{30}$.

debería protegerlo; en cambio lo vuelve loco al punto de matar a su propia esposa Megara y a sus hijos en Heracles de Eurípides. Heracles es el típico triunfador de una cultura: ha matado monstruos e introducido los juegos olímpicos, pero al mismo tiempo es bestial. Sus atuendos también revelan su apasionamiento indomable y llega a ser lo que eventualmente causó su muerte. Desde el punto de vista mítico, Heracles encarna, como ninguno de los héroes griegos, la complejidad naturaleza-cultura.

${ }^{29} \tilde{\eta} v$ : puede considerarse la tercera persona del singular o un forma de $\tilde{\sigma} \sigma \alpha v$. Cf. EASTERLING, 1982, p. 137, n. 517-22.

${ }^{30}$ Deyanira manifiesta su primera impresión sobre las cautivas cuando expresa: oíkтpđì 
El perfil profundo del abatimiento, imposible de derribar, se expone en Deyanira, sentada en el costado, observando, sin poder de decisión. Cipris no ha producido el encuentro, a pesar de que presidió la batalla.

Se profundiza la lucha y la unión de los contrarios en un solo tumulto (517-23). De pronto se ilumina en el foco de atención la figura silente de la novia, brilla distante elevada en la colina y la primera persona singular É $\gamma \omega ́$ sanciona las hazañas que acaban de cantar. Por tanto aparece la singularidad de Cipris al principio y final de $\propto$ y $\alpha$ ', más lejos, las mujeres dan su testimonio. En el centro, ya sea el final de $\alpha$ y el principio de $\alpha$ ", como un continuum se describe la lucha, que prosigue en el comienzo del Epodo.

El canto refleja una diégesis mimética, dramatizable, en cuanto describe el conflicto que dirimieron los dos contendientes. A y a' componen una estructura anular porque comienza con la afirmación de que Cipris siempre conduce hacia la victoria, y finaliza describiendo a Cipris, como jueza de la contienda que llevan a cabo Aqueloo y Heracles.

El estásimo refracta líricamente las expresiones que Deyanira manifiesta en el Episodio I y que describen, muy racionalmente como una sentencia gnómica, el conflicto trágico (441-42):

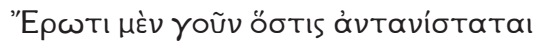

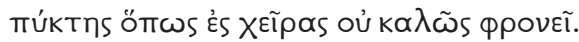

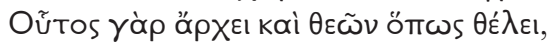
Kåmoũ $\gamma \varepsilon$.

Frente a Eros, el que se coloca como pugilista para llegar a las manos no piensa bien. Pues este gobierna incluso a los dioses como quiere, y también a mí.

Cipris actuó sobre los pretendientes de Deyanira: el río en forma de toro y el hijo de Zeus, Heracles. Deyanira contempla la lucha y esta reminiscencia de la contienda mantiene vigente la influencia de Aqueloo y su mención otorga continuidad al Prólogo monológico en el cual Deyanira se explayó acerca del 'pequeño oráculo' dado por Neso antes de morir. Paradójicamente, este hecho parece olvidado. Las propias mujeres de Traquis expresan su versión sobre la lucha y queda en vilo el poder del Centauro Aqueloo en su relación con los qápuaka antes de que Deyanira resuelva el envío de la túnica. Cuando Deyanira prepara el regalo 
y desata las consecuencias imprevisibles, ella no hace sino reelaborar la lucha primigenia entre ambos.

El estásimo I describe la lucha con el río. En el éxodo, Heracles relata sus victorias sobre los monstruos a los que venció: los gigantes, los centauros (1058-61) y luego prosigue con una nueva mención al león de Nemea, la hidra de Lerna, más Centauros, el jabalí de Erimanto y el can Cerbero, retoño de la Equidna pasmosa. Como un epítome de su vida, el héroe destaca las contiendas más feroces que debió enfrentar. El estásimo, por el contrario, describe sólo una. Heracles ha vencido a Hades, a la tierra, es llamado hijo de Zeus, pero no ha dominado a Deyanira que estuvo imbuida del poder de Eros, que subyuga todos los ámbitos por donde el héroe se destacó en su vida. Dentro de su propia casa se incubaba el salvajismo más descarnado. Paradójico.

De la lucha en el Estásimo I vemos a Heracles postrado en el Éxodo. $\mathrm{Su}$ हैpyov estaba absolutamente concluido, representa su regreso existencial. ${ }^{31}$

La mención de Neso aparece después en el episodio II (555-61), que se conecta con el éxodo, con el reconocimiento de Heracles, y también con la descripción de la muerte de Deyanira, muy semejante a la del monstruo Aqueloo, lo cual la asimila bastante en su aspecto masculinomonstruoso. El agua dulce la ataca, como Aqueloo y también en el río Eveno, cuando Neso pretende obtenerla; por otro lado las aguas saladas del mar la separan de Heracles. El hecho de atravesarlos, tanto el río como el mar, ha encaminado dificultades para ella y, por consiguiente, a Heracles. Deyanira efectivamente ha quedado muy aislada en todos los lugares donde ha vivido ${ }^{32}$. El hijo une el matrimonio por mar, pero entonces entra en funcionamiento en el teatro de Sófocles el desajuste de los tiempos, el acierto esquivo y retrasado en las acciones.

Neso otorga la pócima y aclara el modo de conseguir a Heracles, explica el cómo, mientras que el héroe representa el amor conyugal, el qué. Tanto Neso como Heracles representan dos bestialidades. Para Deyanira, Neso siempre es ó $\theta n ́ p$. J.J. Winkler ${ }^{33}$ afirma que Neso brinda a Deyanira la 'farmacología erótica'; además, la esposa avejentada emplea su 'propio manual de autoayuda', cuando se siente víctima de Eros.

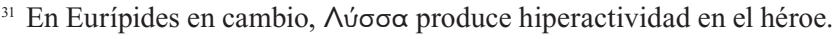

${ }^{32}$ Cf. D.J. Conacher, Sophocles' Trachiniae: Some Observations, AJPh 118, 21-34, 1997.

${ }_{33}$ Las coacciones del deseo. Antropología del sexo y el género en la antigua Grecia, Buenos Aires, Manantial, 1994, p. 96.
} 


\section{Conclusiones}

El estásimo I de Traquinias presenta la clave de la obra porque connota las disyuntivas dramáticas que se despliegan en la escena. Guarda una muy estrecha relación con el prólogo y el éxodo, y no une a Deyanira y Heracles, como tampoco ocurre en Antígona con los jóvenes.

El tema del estásimo más que Eros en sí mismo, presenta la relación de amor y odio. Eros, amor, que incentiva Eris, discordia, y juntos provocan a Ares. Los monstruos destruyen al héroe en el rostro de la belleza femenina. El pintar las pasiones humanas como monstruos o animales grotescos constituye un motivo metafórico en la literatura griega, final-

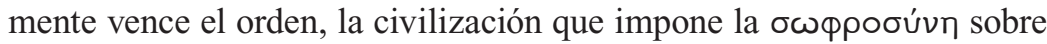

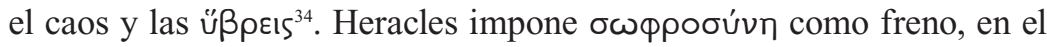
éxodo (vv. 1259-63) una vez consumado el reconocimiento. Finalmente, gana el temperamento pausado, moderado ${ }^{35}$. En Antígona, Creonte padece el reconocimiento de toda la violencia que rodeó sus decisiones.

En el espacio evocado, mítico o distante del estásimo I, Deyanira permanece pasiva como Yole, mientras aguarda silenciosa en el espacio escénico. Por lo tanto el adversario de Heracles renovado en el escenario es representado por Aqueloo-Deyanira. Deyanira llega a ser más monstruosa que los propios monstruos, cuando actúa como reacción, porque como el río Aqueloo, de igual forma muestra rostros diferentes (esposa, madre, hija, novia, extranjera y otros).

En Traquinias, la lucha presenta un ceremonial erótico como para los enemigos (111). Si queremos saber qué significa Eros en los hombres, para el Mensajero alusión, para Licas elipsis, por la mentira, y para Heracles la autoridad femenina desplazada, ha cambiado a su esposa por Yole. Lo paradójico gravita en que Heracles ha cautivado a todas las mujeres a lo largo de sus trabajos y en el regreso él es cautivo de Eros. ${ }^{36}$

${ }^{34}$ Cf. H. North (Sophrosyne. Self-Knowledge and Self-Restraint in Greek Literature, Ithaca, Cornell University Press, 1966, p. 380-81), quien menciona los diversos autores que se han ocupado de plasmar en metáforas la necesidad de restringir el $\theta u \mu o ́ s$, entre otros Platón en Fedro 246a y ss., República 588b, Timeo 70d, Isócrates en Ad Nicoclem 12 y también la Pítica VIII (11 y ss.) de Píndaro.

${ }_{35}$ Cf. Ch. SEgal (Eroismo tragico nelle 'Trachinie' di Sofocle, Dioniso (N.S.) 45, 99111,1971, p. 108) y nuestro libro (2007, p. 154).

${ }^{36}$ Cf. H. Musurillo (Fortune' Whell: The Symbolism of Sophocles' Women of Trachis, TAPhA 92, 372-83, 1961, p. 373), quien afirma lo siguiente: 'But then, with the revelation of the messenger after the entrance of Iole and the captive maidens, we are given a new image of the hero: it is the week Heracles, Heracles the deceiver, Heracles the captive of Eros.' 
Tanto Eros en Antígona como en Traquinias alude a la actividad de fuerzas incontrolables, violentas, que avasallan. Conectadas con zonas liminares, estos poderes despliegan el universo de lo indómito y lo salvaje. Las imágenes bélicas atosigan las estrofas: en Antígona ellas se presentan como víkn, $\lambda \omega \beta$,

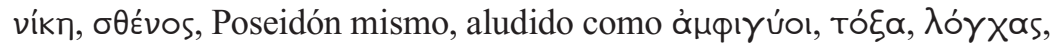

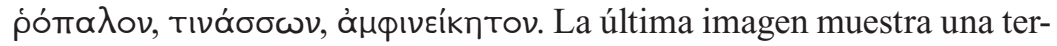
nera desolada que parece la víctima de un sacrificio ritual, con una mansedumbre contrastante y fuera de contexto lo cual despierta desconfianza. En Traquinias Cipris engaña (v. 500) y en Antígona Eros enloquece (v. 781). En ambos coros se describe el poder arrollador que domina todo el universo, da vuelta las cosas y viene por mar. Cipris sale del agua y disuelve a todos.

Título. La presencia de Eros en la poesía dramática de Sófocles

RESÚMEN. Eros está presente en toda la literatura griega. Como rasgo característico de tal fuerza irracional, se afirma que nadie, ni los hombres ni los dioses, se resisten a su influjo. En estas páginas se realiza el análisis filológico-literario del Estásimo III de Antígona y del Estásimo I de Traquinias, donde se describe el poder arrollador de Eros, que domina todo el universo, da vuelta las cosas y viene por mar.

Palabras Claves. Sófocles; drama; Eros, Antígona; Traquinias; estásimos.

\section{TITLE. Eros presence in the dramatic poetry of Sophocles}

ABSTRACT. Eros is present in the whole greek literature. As a main characteristic of such an irrational strength, it is assured that nobody, neither men nor gods, can resist his influence. In these pages it is realized the philological-literary analysis about stasimon III of Antigone and stasimon I of Traquiniae, where the overwhelming power of Eros is described, who controls all of the universe, turns the things and comes from the sea.

KeYwords. Sophocles; drama; Eros; Antigone; Traquiniae; stasima. 